\title{
Construction of copper-based coordination polymers with 1D chain, 2D plane and wavy networks: Syntheses, structures, thermal behavior and photoluminescence properties
}

\author{
JIANGHUA LI ${ }^{\mathrm{a}, *}$ and CHI ZHANG ${ }^{\mathrm{a}, \mathrm{b} *}$ \\ ${ }^{a}$ China-Australia Joint Research Center for Functional Molecular Materials, Scientific Research Academy, \\ Jiangsu University, Zhenjiang 212013, P. R. China \\ ${ }^{\mathrm{b}}$ China-Australia Joint Research Center for Functional Molecular Materials, School of Chemical and Material \\ Engineering, Jiangnan University, Wuxi 214122, P. R. China \\ e-mail: lijianghua2012@ujs.edu.cn; chizhang@ujs.edu.cn
}

MS received 1 May 2015; revised 24 July 2015; accepted 4 August 2015

\begin{abstract}
Three Cu-based coordination polymers (CPs), including $\left[\mathrm{Cu}^{\mathrm{II}}\left(N-\eta^{1}-\mathrm{NCS}\right)_{2}\left(O-\eta^{1}-\mathrm{DMF}\right)_{2}\left(\mu_{2^{-}}\right.\right.$ 3,3'-bptz) $]_{n}(\mathbf{1}),\left[\mathrm{Cu}^{\mathrm{I}}\left(1,3-\mu_{2}-\mathrm{NCS}\right)\left(\mu_{2}-3,3^{\prime}-\mathrm{bptz}\right)\right]_{n}$ (2) and $\left[\left(\mathrm{Cu}^{\mathrm{I}}\left(1,3-\mu_{2}-\mathrm{NCS}\right)\right)\left(\mu_{2}-4,4^{\prime}-\mathrm{bptz}\right)\right]_{n}(\mathbf{3})(\mathrm{DMF}=$ $N, N$-dimethyl formamide, 3,3'-bptz $=3,6$-bis(3-pyridyl)tetrazine and 4,4'-bptz $=3,6$-bis(4-pyridyl)tetrazine) have been successfully constructed by solution diffusion reactions by using $\mathrm{Cu}\left(\mathrm{NO}_{3}\right)_{2} \cdot 3 \mathrm{H}_{2} \mathrm{O}$ or $\mathrm{CuNCS}$ and KNCS with 3,3'-bptz / 4,4'-bptz ligands, respectively. The resulting crystalline materials have been characterized by the single-crystal X-ray diffraction analyses, elemental analyses, FT-IR spectra, thermogravimetric analyses and powder X-ray diffraction (PXRD). Single crystal X-ray analyses revealed that CP $\mathbf{1}$ is organized in one-dimensional (1D) chain in which the $\mathrm{Cu}$ (II) ions are coordinated by $\eta^{1}-\mathrm{NCS}^{-}$anions and $\eta^{1}$-DMF molecules, and linked by $\mu_{2}-3,3^{\prime}$-bptz bridging ligands. CPs $\mathbf{2}$ and $\mathbf{3}$ are structural isomers. CP $\mathbf{2}$ exhibits two-dimensional (2D) (4,4)-plane-like network in which $\mathrm{Cu}(\mathrm{I})$ ions are linked by $\mu_{2}-\mathrm{NCS}^{-}$and $\mu_{2}-3,3^{\prime}$-bptz ligands. In $\mathrm{CP} 3, \mathrm{Cu}(\mathrm{I})$ ions are connected by $\mu_{2} \mathrm{NCS}^{-}$and $\mu_{2}-4,4^{\prime}$-bptz ligands to form 2D saw-tooth wavy network. In addition, the photoluminescence properties of CPs 1-3 were also investigated in the solid state at room temperature.
\end{abstract}

Keywords. Copper; coordination polymers; bis(pyridyl)tetrazine; crystal structures; photoluminescence.

\section{Introduction}

The design and synthesis of coordination polymers (CPs) has attracted significant attention owing to their intriguing aesthetic structures and interesting topologies as well as their potential applications in the fields like photoluminescence, magnetism and nonlinear optics (NLO). ${ }^{1-6}$ As known to all, properties are derived from the natural structure, and also can be subtly moderated by slight structural changes through modification of the ligands or by replacement of the transition metal ions. ${ }^{7,8}$ One of the key points for the rational design of crystalline materials is to understand the intriguing relationship between structures of CPs and the effective factors, but that still seems to be a long-term challenge. ${ }^{9}$

Recently, nitrogen-rich ligands, especially, bis(pyridyl) tetrazine ligands, such as 3,6-bis(3-pyridyl)tetrazine (3,3'-bptz) and the isomeric 3,6-bis(4-pyridyl)tetrazine

\footnotetext{
*For correspondence
}

(4,4'-bptz) ligands, have been well used as a coordinative $\pi$-acceptor moiety of CPs assemblies. ${ }^{10,11}$ However, CPs constructed from bis(pyridyl)tetrazine and metal pseudohalides are relatively scarce. ${ }^{12}$ To extend this scope, we focused on constructing new $\mathrm{CPs}$ of $\mathrm{Cu}(\mathrm{I} / \mathrm{II})$ pseudohalides, as well as enriching the coordination chemistry of bis(pyridyl)tetrazine ligands. Importantly, we chose them as functional building blocks based on the following considerations: a) the flexibility of $\mathrm{Cu}(\mathrm{I} / \mathrm{II})$ coordination sphere, varying from trigonal, tetragonal and octahedral, affording a good opportunity to predict structures of CPs in selfassembly process,${ }^{13-15}$ b) on account of the difference in $N$-coordination sites and lengths of isomeric ligands (scheme 1), together with an ambidentate ligand thiocyanate, the final CPs should exhibit conformational and configuration versatility; ${ }^{16}$ c) significantly, the CPs incorporating bis(pyridyl)tetrazine ligands may have excellent photoluminescence properties because tetrazine is a typical organic chromophore. ${ }^{17}$

We report the construction (scheme 2), structures and luminescence properties of three $\mathrm{Cu}$-based CPs with 

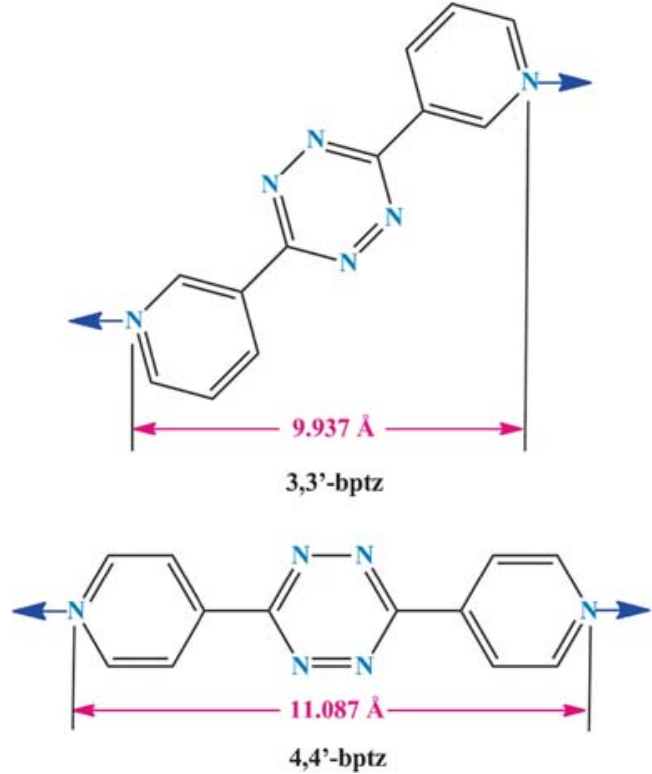

Scheme 1. Difference between the 3,3'-bptz and 4,4'-bptz ligands in $N$-coordination sites and lengths.

pseudohalides and bptz isomeric ligands: $\left[\mathrm{Cu}^{\mathrm{II}}\left(N-\eta^{1}-\right.\right.$ $\left.\mathrm{NCS})_{2}\left(O-\eta^{1}-\mathrm{DMF}\right)_{2}\left(\mu_{2}-3,3^{\prime}-\mathrm{bptz}\right)\right]_{n}$ (1) $\left[\mathrm{Cu}^{\mathrm{I}}\left(1,3-\mu_{2}-\right.\right.$ $\left.\mathrm{NCS})\left(\mu_{2}-3,3^{\prime}-\mathrm{bptz}\right)\right]_{n}(2)$ and $\left[\left(\mathrm{Cu}^{\mathrm{I}}\left(1,3-\mu_{2}-\mathrm{NCS}\right)\right)\left(\mu_{2^{-}}\right.\right.$ $4,4^{\prime}$-bptz) $]_{n}(\mathbf{3})$.

\section{Experimental}

\subsection{Materials and physical measurements}

The ligands 3,3'-bptz and 4,4'-bptz were prepared according to the literature procedures. ${ }^{18}$ All the reagents and solvents for the syntheses and analyses were commercially available and used as received. Elemental analyses for carbon, hydrogen, and nitrogen were performed on a FLASH 1112A elemental analyzer. Infrared spectra were recorded with a Nicolet Nexus 470 Fourier transform spectrometer ( $\mathrm{KBr}$ pellets). Steady-state fluorescence spectra were measured with a PTI QM 40 spectrofluorometer. The powder X-ray diffraction (PXRD) measurements were recorded on a Bruker D8 ADVANCE powder X-ray diffractometer $(\mathrm{Cu} K \alpha=1.5418 \AA)$. Thermogravimetric analyses were performed on a Netzsch STA-449C thermoanalyzer with a $\mathrm{N}_{2}$ purge and a heating rate of $10^{\circ} \mathrm{C} / \mathrm{min}$.

2.2 Synthesis of $\left[C u^{I I}\left(N-\eta^{1}-N C S\right)_{2}\left(O-\eta^{1}-D M F\right)_{2}\left(\mu_{2}-3\right.\right.$, 3'-bptz) $]_{n}(\mathbf{1})$

$\mathrm{Cu}\left(\mathrm{NO}_{3}\right)_{2} \cdot 3 \mathrm{H}_{2} \mathrm{O}(0.484 \mathrm{~g}, 0.200 \mathrm{mmol})$ and $\mathrm{KNCS}$ $(0.194 \mathrm{~g}, 0.200 \mathrm{mmol})$ in a $N, N$-dimethyl formamide

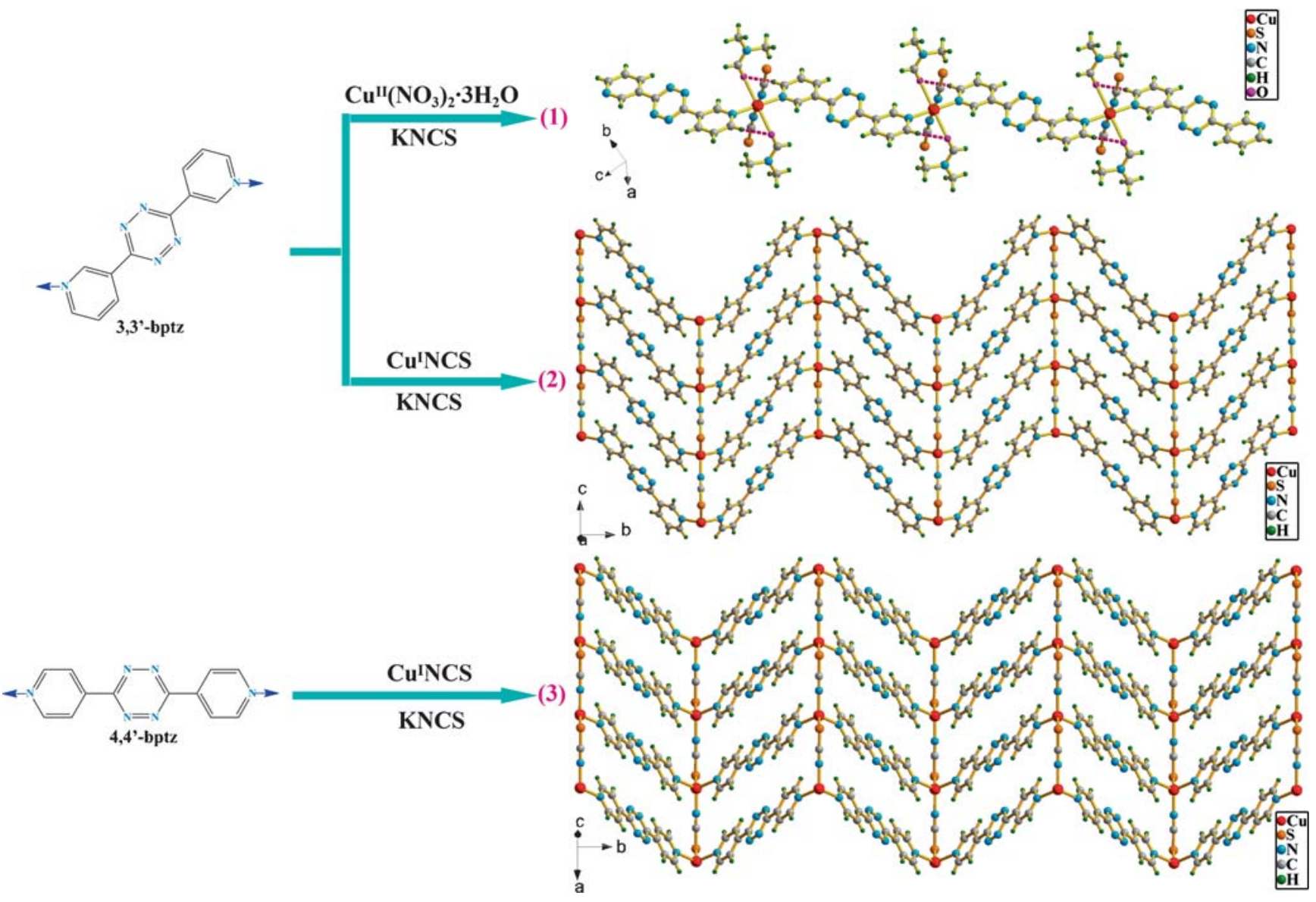

Scheme 2. The syntheses of $\mathbf{1 - 3}$ from reactions of $\mathrm{Cu}(\mathrm{I} / \mathrm{II})$ and KNCS with 3,3'-bptz / 4,4'-bptz ligands. 
(DMF, $5.00 \mathrm{~mL}$ ) were stirred and filtered. Filtrated solution were carefully layered over $10 \mathrm{~mL} 3,3$ 'bptz/ $\mathrm{CH}_{2} \mathrm{Cl}_{2}\left(0.100 \mathrm{~mol} \mathrm{~L}^{-1}\right)$. Red block single crystals of 1 (Yield: $39.3 \mathrm{mg}, 0.0700 \mathrm{mmol}, 35 \%$ based on $\mathrm{Cu})$ were obtained after two weeks at room temperature. Anal. calcd for $\mathrm{C}_{20} \mathrm{H}_{22} \mathrm{CuN}_{10} \mathrm{O}_{2} \mathrm{~S}_{2}$ : C, 42.73\%; H, 3.94\%; N, 24.92\%. Found: C, 42.86\%; H, 3.95\%; $\mathrm{N}, 25.01 \%$; FT-IR frequencies $\left(\mathrm{KBr}, \mathrm{cm}^{-1}\right) 2088 \mathrm{vs}$, $1652 \mathrm{vs}, 1604 \mathrm{w}, 1441 \mathrm{w}, 1391 \mathrm{vs}, 1123 \mathrm{~s}, 1053 \mathrm{w}, 916 \mathrm{w}$, 813w, 699w, 474w.

\subsection{Synthesis of $\left[C u^{I}\left(1,3-\mu_{2}-N C S\right)\left(\mu_{2}-3,3^{\prime}-b p t z\right)\right]_{n}$}

CP 2 was obtained as red block crystals by the same procedure as that of $\mathbf{1}$, except that CuNCS $(0.244 \mathrm{mg}$, $0.200 \mathrm{mmol}$ ) was used instead of $\mathrm{Cu}\left(\mathrm{NO}_{3}\right)_{2} \cdot 3 \mathrm{H}_{2} \mathrm{O}$ $(0.484 \mathrm{~g}, 0.200 \mathrm{mmol})$. Yield: $20.0 \mathrm{mg}, 0.0560 \mathrm{mmol}$, $28 \%$ based on $\mathrm{Cu}$. Anal. calcd for $\mathrm{C}_{13} \mathrm{H}_{8} \mathrm{CuN}_{7} \mathrm{~S}$ : C, 43.59\%; H, 2.24\%; N, 27.38\%. Found: C, 43.98\%; $\mathrm{H}, 2.63 \%$; N, 27.70\%; FT-IR frequencies $\left(\mathrm{KBr}, \mathrm{cm}^{-1}\right)$ 2092vs, 1587s, 1436w, 1385vs, 1106w, 1022w, 914w, $813 \mathrm{w}, 692 \mathrm{~s}, 601 \mathrm{~s}, 443 \mathrm{w}$.

\subsection{Synthesis of $\left[\left(C u^{I}\left(1,3-\mu_{2}-N C S\right)\right)\left(\mu_{2}-4,4^{\prime}-b p t z\right)\right]_{n}(3)$}

CP 3 was obtained as red block crystals by the same procedure as that of 2 , except that $4,4^{\prime}$-bptz $/ \mathrm{CH}_{2} \mathrm{Cl}_{2}$ $\left(0.100 \mathrm{~mol} \mathrm{~L}^{-1}\right)$ was used instead of 3,3'-bptz/ $\mathrm{CH}_{2} \mathrm{Cl}_{2}$ $\left(0.100 \mathrm{~mol} \mathrm{~L}^{-1}\right)$. Yield: $20.7 \mathrm{mg}, 0.0580 \mathrm{mmol}, 29 \%$ based on $\mathrm{Cu}$. Anal. calcd for $\mathrm{C}_{13} \mathrm{H}_{8} \mathrm{CuN}_{7} \mathrm{~S}$ : C, 43.59\%; H, 2.24\%; N, 27.38\%. Found: C, 43.92\%; H, 2.58\%; $\mathrm{N}, 27.66 \%$; FT-IR frequencies $\left(\mathrm{KBr}, \mathrm{cm}^{-1}\right) 2137 \mathrm{vs}$, 1666vs, 1604s, 1559vs, 1392vs, 1115w, 1057w, 922w, $831 \mathrm{w}, 723 \mathrm{w}, 598 \mathrm{~s}, 434 \mathrm{w}$.

\subsection{Crystal Structure Determination}

Suitable crystals of 1-3 for single crystal X-ray analyses were obtained directly from the above preparations. All the measurements were made on a Rigaku Saturn 724+ CCD X-ray diffractometer by using graphite monochromated Mo $K \alpha$ radiation $(\lambda=0.71070 \AA)$. Single crystals of 1-3 were mounted with grease at the top of a glass fiber. Cell parameters were refined on all observed reflections by using the program CrystalClear. ${ }^{19}$ The collected data were reduced by the program CrystalClear and an absorption correction (multiscan) was applied. The reflection data for 1-3 were also corrected for Lorentz and polarization effects. The crystal structures of 1-3 were solved by direct methods and refined on $F^{2}$ by full-matrix least-squares methods using the SHELXTL software package..$^{20}$ All nonhydrogen atoms of 1-3 were refined anisotropically. All hydrogen atoms of 1-3 were placed in geometrically idealized positions and constrained to ride on their

Table 1. Crystal data and structure refinements for CPs 1-3.

\begin{tabular}{|c|c|c|c|}
\hline CPs & 1 & 2 & 3 \\
\hline Molecular formula & $\mathrm{C}_{20} \mathrm{H}_{22} \mathrm{CuN}_{10} \mathrm{O}_{2} \mathrm{~S}_{2}$ & $\mathrm{C}_{13} \mathrm{H}_{8} \mathrm{CuN}_{7} \mathrm{~S}$ & $\mathrm{C}_{13} \mathrm{H}_{8} \mathrm{CuN}_{7} \mathrm{~S}$ \\
\hline Formula weight & 562.14 & 357.88 & 357.86 \\
\hline$T(\mathrm{~K})$ & $293(2)$ & $293(2)$ & $293(2)$ \\
\hline Crystal system & Triclinic & Monoclinic & Monoclinic \\
\hline Space group & $P-1$ & $P 2_{1} / m$ & $P 2_{1} / m$ \\
\hline$a / \AA$ & $7.2494(14)$ & $5.5494(11)$ & $5.8640(12)$ \\
\hline$b / \AA$ & $9.1431(18)$ & $20.688(4)$ & $18.510(4)$ \\
\hline$c / \AA$ & $12.370(3)$ & $5.8832(12)$ & $6.3993(13)$ \\
\hline$\alpha /^{\circ}$ & $107.40(3)$ & 90 & 90 \\
\hline$\beta /{ }^{\circ}$ & $92.38(3)$ & $98.04(3)$ & $104.42(3)$ \\
\hline$\gamma /{ }^{\circ}$ & $102.99(3)$ & 90 & 90 \\
\hline$V / \AA^{3}$ & $757.1(3)$ & $668.8(2)$ & $672.7(2)$ \\
\hline Z & 1 & 2 & 2 \\
\hline$D c / \mathrm{g} \mathrm{cm}^{-3}$ & 1.233 & 1.777 & 1.767 \\
\hline$\mu / \mathrm{mm}^{-1}$ & 0.910 & 1.795 & 1.785 \\
\hline$F(000)$ & 361 & 360 & 360 \\
\hline Reflections collected & 5508 & 3230 & 3288 \\
\hline Unique reflections & 2634 & 1328 & 1373 \\
\hline$R_{\text {int }}$ & 0.0317 & 0.0286 & 0.0182 \\
\hline No. parameters & 162 & 106 & 106 \\
\hline GOOF & 1.120 & 1.105 & 1.051 \\
\hline$R_{1} / w R_{2}[I>2 \sigma(I)]$ & 0.0964 / 0.3189 & $0.0391 / 0.0696$ & $0.0327 / 0.0704$ \\
\hline$\Delta \rho_{\max } / \Delta \rho_{\min }\left(\mathrm{e} \AA^{-3}\right)$ & $2.520 /-0.575$ & $0.380 /-0.409$ & $0.484 /-0.355$ \\
\hline
\end{tabular}


Table 2. Selected bonds lengths $(\AA)$ and angles $\left({ }^{\circ}\right)$ for CPs $\mathbf{1 - 3}{ }^{a}$.

\begin{tabular}{lccc}
\hline & & & \\
$\mathrm{Cu}(1)-\mathrm{N}(2)$ & $1.962(7)$ & $\mathrm{Cu}(1)-\mathrm{N}(2) \# 1$ & $1.962(7)$ \\
$\mathrm{Cu}(1)-\mathrm{N}(1) \# 1$ & $2.018(6)$ & $\mathrm{Cu}(1)-\mathrm{N}(1)$ & $2.018(6)$ \\
$\mathrm{Cu}(1)-\mathrm{O}(1)$ & $2.441(5)$ & & $180.0(3)$ \\
$\mathrm{N}(2)-\mathrm{Cu}(1)-\mathrm{N}(1)$ & $89.5(3)$ & $\mathrm{N}(2)-\mathrm{Cu}(1)-\mathrm{N}(2) \# 1$ & $90.5(3)$ \\
$\mathrm{N}(2) \# 1-\mathrm{Cu}(1)-\mathrm{N}(1)$ & $90.5(3)$ & $\mathrm{N}(2)-\mathrm{Cu}(1)-\mathrm{N}(1) \# 1$ & $89.5(3)$ \\
$\mathrm{N}(1)-\mathrm{Cu}(1)-\mathrm{N}(1) \# 1$ & $180.0(1)$ & $\mathrm{N}(2) \# 1-\mathrm{Cu}(1)-\mathrm{N}(1) \# 1$ & \\
& & & $2.101(2)$ \\
& & & $2.2873(14)$ \\
$\mathrm{Cu}(1)-\mathrm{N}(4) \# 1$ & 2 & $\mathrm{Cu}(1)-\mathrm{N}(1) \# 2$ & $105.36(9)$ \\
$\mathrm{Cu}(1)-\mathrm{N}(1)$ & $1.959(3)$ & $\mathrm{Cu}(1)-\mathrm{S}(1)$ & $119.95(11)$ \\
$\mathrm{N}(4) \# 1-\mathrm{Cu}(1)-\mathrm{N}(1)$ & $2.101(2)$ & $\mathrm{N}(4) \# 1-\mathrm{Cu}(1)-\mathrm{N}(1) \# 2$ & $165.0(3)$ \\
$\mathrm{N}(1) \# 2-\mathrm{Cu}(1)-\mathrm{N}(1)$ & $105.36(9)$ & $\mathrm{N}(4) \# 1-\mathrm{Cu}(1)-\mathrm{S}(1)$ & \\
$\mathrm{N}(1)-\mathrm{Cu}(1)-\mathrm{S}(1)$ & $105.42(13)$ & $\mathrm{C}(1) \# 2-\mathrm{Cu}(1)-\mathrm{S}(1)$ & \\
$\mathrm{C}(7)-\mathrm{S}(1)-\mathrm{Cu}(1)$ & $109.86(6)-\mathrm{Cu}(1) \# 4$ & $2.100(2)$ \\
& $101.14(14)$ & & $2.2551(13)$ \\
$\mathrm{Cu}(1)-\mathrm{N}(2) \# 1$ & & $\mathrm{Cu}(1)-\mathrm{N}(1) \# 2$ & $108.87(8)$ \\
$\mathrm{Cu}(1)-\mathrm{N}(1)$ & & $\mathrm{Cu}(1)-\mathrm{S}(1)$ & $116.81(10)$ \\
$\mathrm{N}(2) \# 1-\mathrm{Cu}(1)-\mathrm{N}(1)$ & $1.948(3)$ & $\mathrm{N}(2) \# 1-\mathrm{Cu}(1)-\mathrm{N}(1) \# 2$ & $111.56(6)$ \\
$\mathrm{N}(1) \# 2-\mathrm{Cu}(1)-\mathrm{N}(1)$ & $108.87(8)$ & $\mathrm{N}(2) \# 1-\mathrm{Cu}(1)-\mathrm{S}(1)$ & $\mathrm{N}(1) \# 2-\mathrm{Cu}(1)-\mathrm{S}(1)$ \\
$\mathrm{N}(1)-\mathrm{Cu}(1)-\mathrm{S}(1)$ & $97.43(12)$ & & \\
\hline
\end{tabular}

${ }^{a}$ Symmetry transformations used to generate equivalent atoms: For 1, \#1: $-\mathrm{x}+1,-\mathrm{y}+2,-\mathrm{z}+1$; for 2, \#1: x, y, z-1; \#2: x, -y+1/2, z; \#4 x, y, z+1; for 3, \#1: x, y, z-1; \#2: x, -y+1/2, z.

parent atoms. The R index of $\mathbf{1}$ was high, which may be an artifact of part of disorder in the structure of $\mathrm{NCS}^{-}$ and DMF. Crystallographic data and structural refinement parameters for 1-3 are summarized in table 1 . Selected bond lengths and bond angles for 1-3 are listed in table 2.

\section{Results and Discussion}

\subsection{Crystal structure of $\left[C u^{I I}\left(N-\eta^{1}-N C S\right)_{2}\right.$ $\left.\left(O-\eta^{1}-D M F\right)_{2}\left(\mu_{2}-3,3^{\prime}-b p t z\right)\right]_{n}(\mathbf{1})$}

Single-crystal X-ray analysis has revealed that $\mathbf{1}$ crystallizes in the monoclinic space group $P-1$, which is an infinite 1D coordination polymer. There are one $\mathrm{Cu}(\mathrm{II})$ ion, half $3,3^{\prime}$-bptz, one $\mathrm{NCS}^{-}$and one DMF molecule in the asymmetric unit (figure 1a). The sixcoordinated $\mathrm{Cu}(\mathrm{II})$ adopts a distorted octahedral coordination geometry $[\mathrm{Cu}(1)-\mathrm{N}(2)=1.963(6) \AA, \mathrm{Cu}(1)$ $\mathrm{N}(1)=2.019(6) \AA, \mathrm{Cu}(1)-\mathrm{O}(1)=2.441(5) \AA]$ which is completed by two $\mathrm{N}$ atoms from bridging $3,3^{\prime}$-bptz ligands, two $\mathrm{N}$ atoms from terminal $\mathrm{NCS}^{-}$and two $\mathrm{O}$ atoms from terminal DMF as shown in figure 1b. The elongation of the $\mathrm{Cu}-\mathrm{O}$ distance may be ascribed to the Jahn-Teller effect ${ }^{21}$ which reduces the thermal stability. The nitrogen atoms of two thiocyanate ligands and oxygen atoms of two DMF molecules lie face to face in the equatorial plane. Although $\mathrm{NCS}^{-}$ligand often plays as a bridging ligand, in CP $\mathbf{1}$ it acts as a terminal ligand with $\mathrm{N}$ coordinated with $\mathrm{Cu}$ (II) which demonstrates that $\mathrm{Cu}$ (II) be inclined to nitrophilic. ${ }^{22}$ The 3,3'-bptz ligands further act as a linker resulting in $1 \mathrm{D}$ chains approximately along the $a$ axis (figure 1c). In these chains, atoms $\mathrm{C} 1$ of 3,3'-bptz ligands and $\mathrm{O} 1$ of DMF molecule take part in $\mathrm{C}-\mathrm{H}$. . O hydrogen bonding $[\mathrm{C} 1-\mathrm{H} 1 \mathrm{~A} \cdots \mathrm{O} 1=3.352(2) \AA ̊$; Symmetry code: $-\mathrm{x}$, 2-y, 1-z; figure 1c and table 3]. These 1D linear chains are packed parallelly in the solid to achieve porous architecture (figure 1d).

\subsection{Crystal structure of $\left[C u^{I}\left(1,3-\mu_{2}-N C S\right)\right.$ $\left.\left(\mu_{2}-3,3 '-b p t z\right)\right]_{n}(2)$}

Single crystal X-ray diffraction analysis reveals that $\mathbf{2}$ has 2D $(4,4)$ nearly plane-like structure, which is built up from parallel $1 \mathrm{D}$ zigzag $[\mathrm{Cu}(\mathrm{NCS})]_{n}$ chains, linked by the bridging ligand 3,3'-bptz (figure 2). The asymmetric unit of $\mathbf{2}$ consists of a $\mathrm{Cu}$ center, half 3,3'-bptz and one $\mathrm{NCS}^{-}$(figure 2a). The $\mathrm{Cu} 1$ is four coordinated by two $\mathrm{N}$ atoms from two 3,3'-bptz ligands, and one $\mathrm{N}$ atom and one $\mathrm{S}$ atom from two $\mathrm{NCS}^{-}$. The two linear $\mathrm{NCS}^{-}$anions are not perpendicular to the equatorial plane and the $\mathrm{C}(7)-\mathrm{S}(1)-\mathrm{Cu}(1)$ and $\mathrm{C}(7)-\mathrm{N}(4)-$ $\mathrm{Cu}(1)$ angles are 101.14(14) and 165.00(3) as shown in table 2. The two trans-3,3'-bptz ligands in the coordination environment of molecular structure with $\sigma_{\mathrm{v}}$ symmetry are like the wings of a spread eagle (figure $2 \mathrm{~b})$. As a result, the adjacent $\mathrm{Cu}$ centers are connected by the $\mathrm{NCS}^{-}$linkers to generate $1 \mathrm{D}$ zigzag $[\mathrm{Cu}(\mathrm{NCS})]_{\mathrm{n}}$ chain array with the 3,3'-bptz ligands outspread at both 


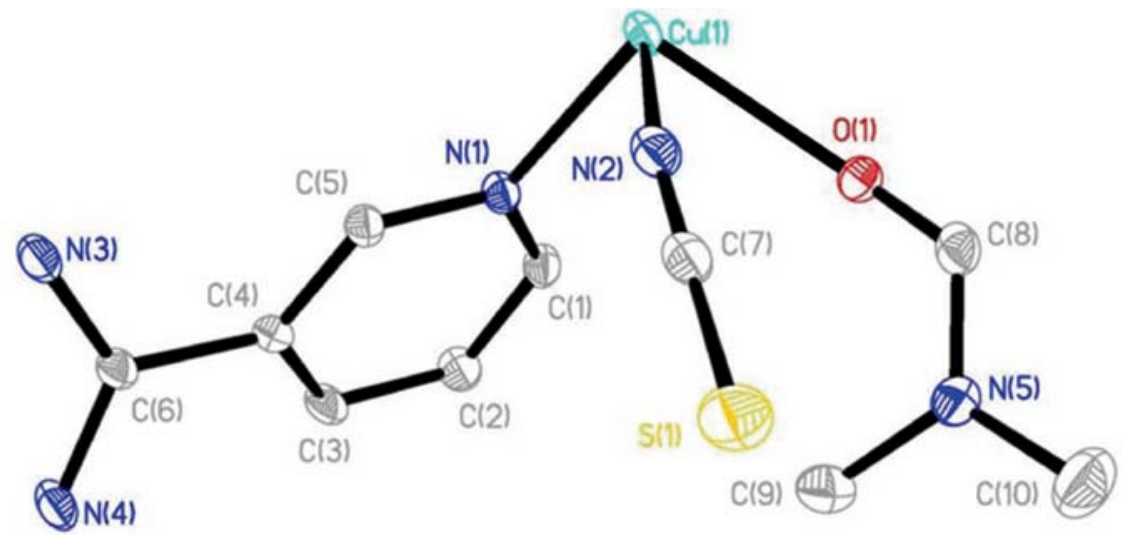

(a)

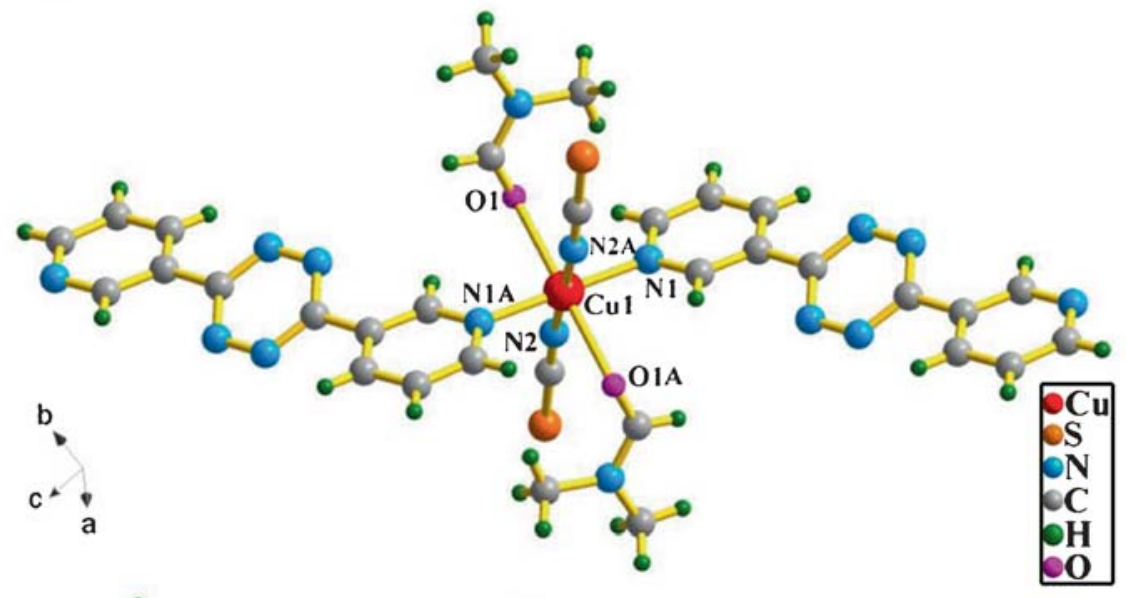

(b)

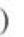
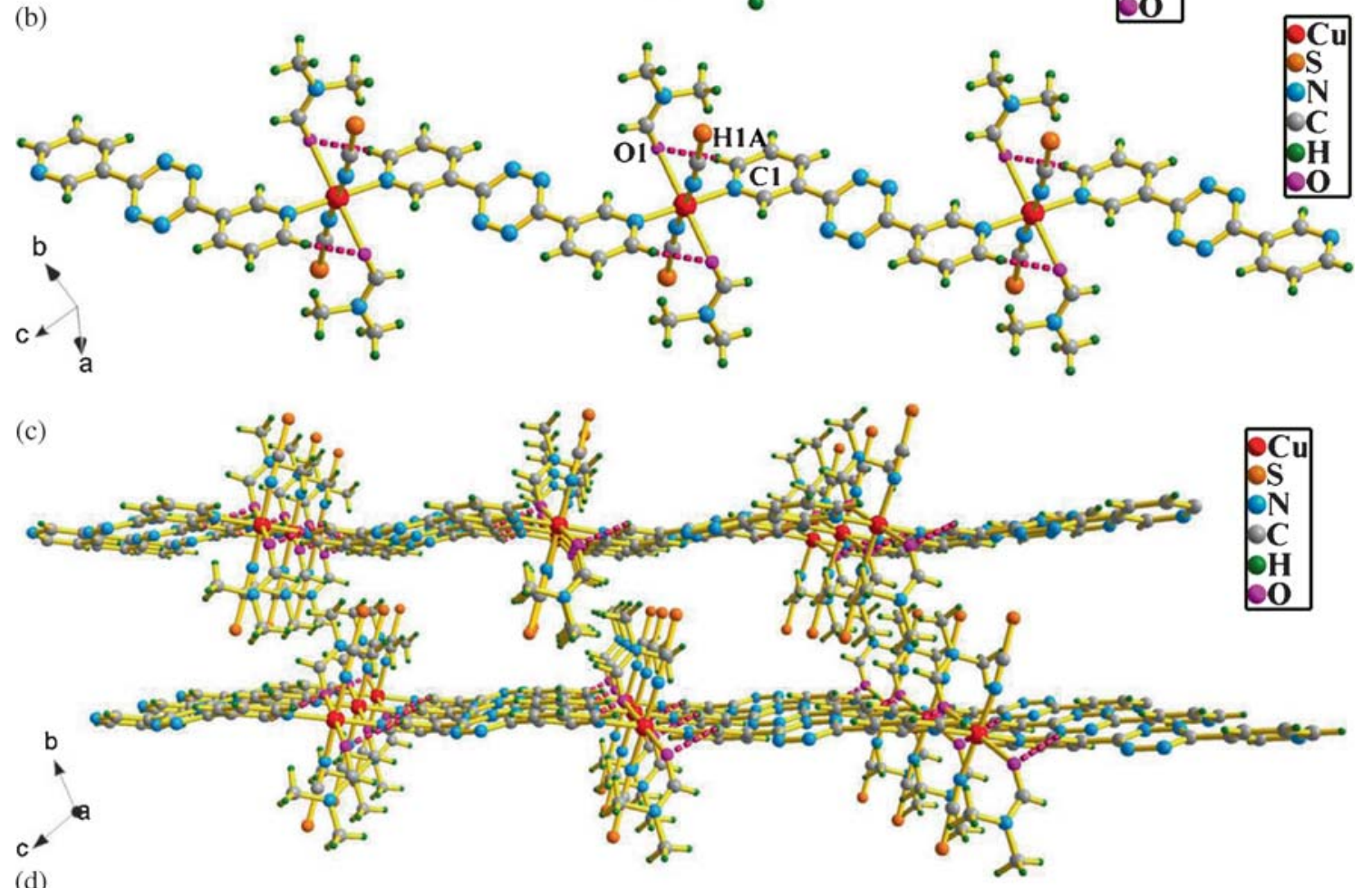

Figure 1. (a) The asymmetric unit of $\mathbf{1}$ (30\% probability ellipsoids). (b) A local view showing the coordination geometry of $\mathrm{Cu}(\mathrm{II})$. Symmetry code: $a$ : $\mathrm{x}, \mathrm{y}, \mathrm{z} ; b$ : -x, -y, -z. (c) The 1D chain of 1 viewed approximately down the $a$-axis. The C-H $\cdots$ O hydrogen bonds are shown as purple red dotted lines. Symmetry code: $a$ : x, y, z. (d) Packing diagram of $\mathbf{1}$ viewed approximately down the $c$-axis. 
Table 3. Hydrogen bond parameters (distances in $\AA$ and angles in ${ }^{\circ}$ ) of $\mathbf{1}$.

\begin{tabular}{lcccc}
\hline $\mathrm{D}-\mathrm{H} \cdots \mathrm{A}$ & $\mathrm{d}(\mathrm{D}-\mathrm{H})$ & $\mathrm{d}(\mathrm{H} \cdots \mathrm{A})$ & $\mathrm{d}(\mathrm{D} \cdots \mathrm{A})$ & $\angle(\mathrm{D}-\mathrm{H} \cdots \mathrm{A})$ \\
\hline $\mathrm{C} 2-\mathrm{H} 1 \mathrm{~A} \cdots \mathrm{O}^{\mathrm{a}}$ & 0.93 & 2.60 & $3.352(2)$ & 139
\end{tabular}

Symmetry transformations used to generate equivalent atoms: ${ }^{\mathrm{a}}-\mathrm{x}, 2-\mathrm{y}, 1-\mathrm{z}$.

sides to form 2D $(4,4)$ plane-like structure (figure $2 \mathrm{c}$ ), and the lengths of the two diagonals in the grid, constructed by two [Cu-SCN-Cu] units and two 3,3'-bptz bridges, are 11.042(19) and 17.361(28) , respectively (figure 2c). Interestingly, viewed along the $c$-axis, the packing diagram of $\mathbf{2}$ shows a nearly plane-like layer stacked in an interesting $\mathrm{ABAB}$ fashion (figure 2d).

\subsection{Crystal structure of $\left[\left(\mathrm{Cu}^{I}\left(1,3-\mu_{2}-N C S\right)\right)\right.$ $\left.\left(\mu_{2}-4,4^{\prime}-b p t z\right)\right]_{n}(3)$}

CPs $\mathbf{2}$ and $\mathbf{3}$ are structural isomers, and $\mathbf{3}$ displays a 2D wave-like structure (figure 3 ) which has been briefly reported by our group. ${ }^{23}$ The asymmetric unit of $\mathbf{3}$ consists of a $\mathrm{Cu}$ center, half 4,4'-bptz and one $\mathrm{NCS}^{-}$ (figure $3 \mathrm{a}$ ). The $\mathrm{Cu}(\mathrm{I})$ atoms exhibit a distorted tetrahedral geometry. Each $\mathrm{Cu} 1$ ion is surrounded by two pyridyl $\mathrm{N}$ donor from a pair of 4,4'-bptz and one $\mathrm{N}$ atom of a $\mathrm{NCS}^{-}$and one $\mathrm{S}$ from another $\mathrm{NCS}^{-}$(figure $3 b)$. As a result, all -Cu-NCS-Cu- linker modes produce 1D zigzag chains. However, they are connected by 4,4'-bptz ligands outspread at both sides to form 2D $(4,4)$ sawtooth wavy network (figure $3 \mathrm{c}$ ), and the lengths of the two diagonals in the grid, constructed by two $[\mathrm{Cu}-\mathrm{SCN}-\mathrm{Cu}]$ units and two 3,3'-bptz bridges, are 15.191(32) and 17.284(31) , respectively (figure 3c). Viewed along the $a$-axis, the sheet in $\mathbf{3}$ is corrugated with a dihedral angle of $75.144(1)^{\circ}$ between adjacent grids and are packed in parallel fashion in the crystal lattice (figure 3d). Owing to the position of pyridyl- $N$ and $N$-coordinated distance of 3,3'-bptz and 4,4'-bptz ligands, the $2 \mathrm{D}$ pattern and packing diagram are distinct for $\mathbf{2}$ and $\mathbf{3}$.

\subsection{The factors in the formation of CPs 1-3}

Formation of the CPs can be influenced by many factors in the process of synthesis reaction and crystal growth. CPs 1-3 were prepared under liquid diffusion assembly method. CP $\mathbf{1}$ was obtained in DMF soultion of $\mathrm{Cu}\left(\mathrm{NO}_{3}\right)_{2} \cdot 3 \mathrm{H}_{2} \mathrm{O}$ and $\mathrm{KNCS}$ which diffuse to 3,3'-bptz in $\mathrm{CH}_{2} \mathrm{Cl}_{2}$ solution via self-assembly process. The $\mathrm{N}$ atoms of $\mathrm{NCS}^{-}$anions are coordinated to $\mathrm{Cu}^{2+}$ cations rather than $\mathrm{NO}_{3}^{-}$anions because the capability of coordination for $\mathrm{NCS}^{-}$anion is superior to $\mathrm{NO}_{3}^{-}$ anion. Meanwhile, according to the theory of Hard and Soft Acids and Bases, $\mathrm{Cu}^{2+}$ cations are soft acid, $\mathrm{N}$ atoms are soft base, and $\mathrm{S}$ atoms are hard acid, it can be explained that $\mathrm{N}$ atoms coordinated with $\mathrm{Cu}^{2+}$ cations but not $\mathrm{S}$ of $\mathrm{NCS}^{-}$anions. In addition, $\mathrm{O}$ atoms from DMF molecules and $\mathrm{N}$ atoms of 3,3'-bptz ligands are coordinated with $\mathrm{Cu}^{2+}$ cations to form stabilized coordinated geometrical configuration. Then, the final structure of CP $\mathbf{1}$ is $1 \mathrm{D}$ chain. In CP $\mathbf{2}$ and $\mathbf{3}$, the copper salt is $\mathrm{CuNCS}$, the $\mathrm{NCS}^{-}$anions serve as $\mu_{2}$ - bridge ligands, combined with $\mu_{2}-3,3$ '-bptz and $\mu_{2}-4,4$ ' -bptz ligands. Thus, CPs $\mathbf{2}$ and $\mathbf{3}$ display 2D networks. In virtue of the coordinated sites and lengths of isomeric ligands, CP 2 shows 2D plane-like network while CP $\mathbf{3}$ form 2D sawtooth wavy network. Therefore, the valence of metal ions, the capability of coordination ligands, coordination sites and lengths of ligands can influence the dimensionality and configuration of CPs. The results described above show that these factors can be useful for designing and constructing new CPs materials.

\subsection{Electron paramagnetic resonance (EPR) spectrum of 1}

In order to demonstrate the valence of $\mathrm{Cu}$ in $\mathrm{CP} \mathbf{1}$, EPR spectrum of $\mathbf{1}$ has been characterized. As shown in figure 4, the EPR spectrum of $\mathbf{1}$ manifested resonance signals similar to those compounds including $\mathrm{Cu}^{2+}$ reported in literature. ${ }^{24,25}$ Therefore, the valence of $\mathrm{Cu}$ in compound $\mathbf{1}$ is plus 2 .

\section{$3.6 \quad$ FT-IR spectra}

The FT-IR spectra of CPs 1-3 are shown in figure S1 (Supplementary Information). All the CPs show $\mathrm{C} \equiv \mathrm{N}$ bands in frequency around $2100 \mathrm{~cm}^{-1}\left(2088 \mathrm{~cm}^{-1}\right.$ in $\mathbf{1}$, $2092 \mathrm{~cm}^{-1}$ in 2 and $2137 \mathrm{~cm}^{-1}$ in 3 ) and $\mathrm{S}-\mathrm{C}$ bands in the region $692-922 \mathrm{~cm}^{-1}$ which are confirmed by the literature. ${ }^{26}$ In the spectrum of $\mathbf{1}$, the doubling band around $2900 \mathrm{~cm}^{-1}$ is the characteristic absorption of aldehyde and $1652 \mathrm{~cm}^{-1}$ should be the $\mathrm{C}=\mathrm{O}$ stretching vibration from DMF. Two or three peaks in 1604$1500 \mathrm{~cm}^{-1}$ should be the aromatic skeleton vibrations of pyridine and the ring stretches of tetrazine are around $1500-1385 \mathrm{~cm}^{-1} \cdot{ }^{27}$ The IR spectrum of $\mathbf{3}$ is very similar to that of $\mathbf{2}$, which indicates their similar stretching vibration groups in structures.

\subsection{Powder X-ray diffraction and thermal behavior}

To corroborate whether the molecular structures are truly representative of the bulk crystal materials and 
(a)

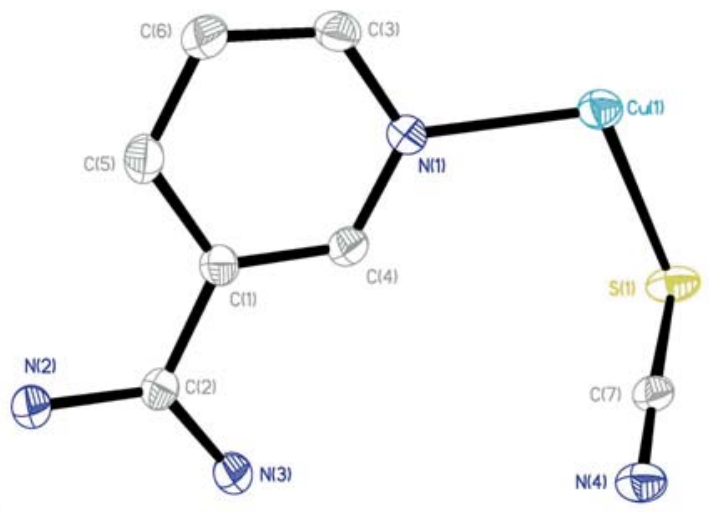

(b)
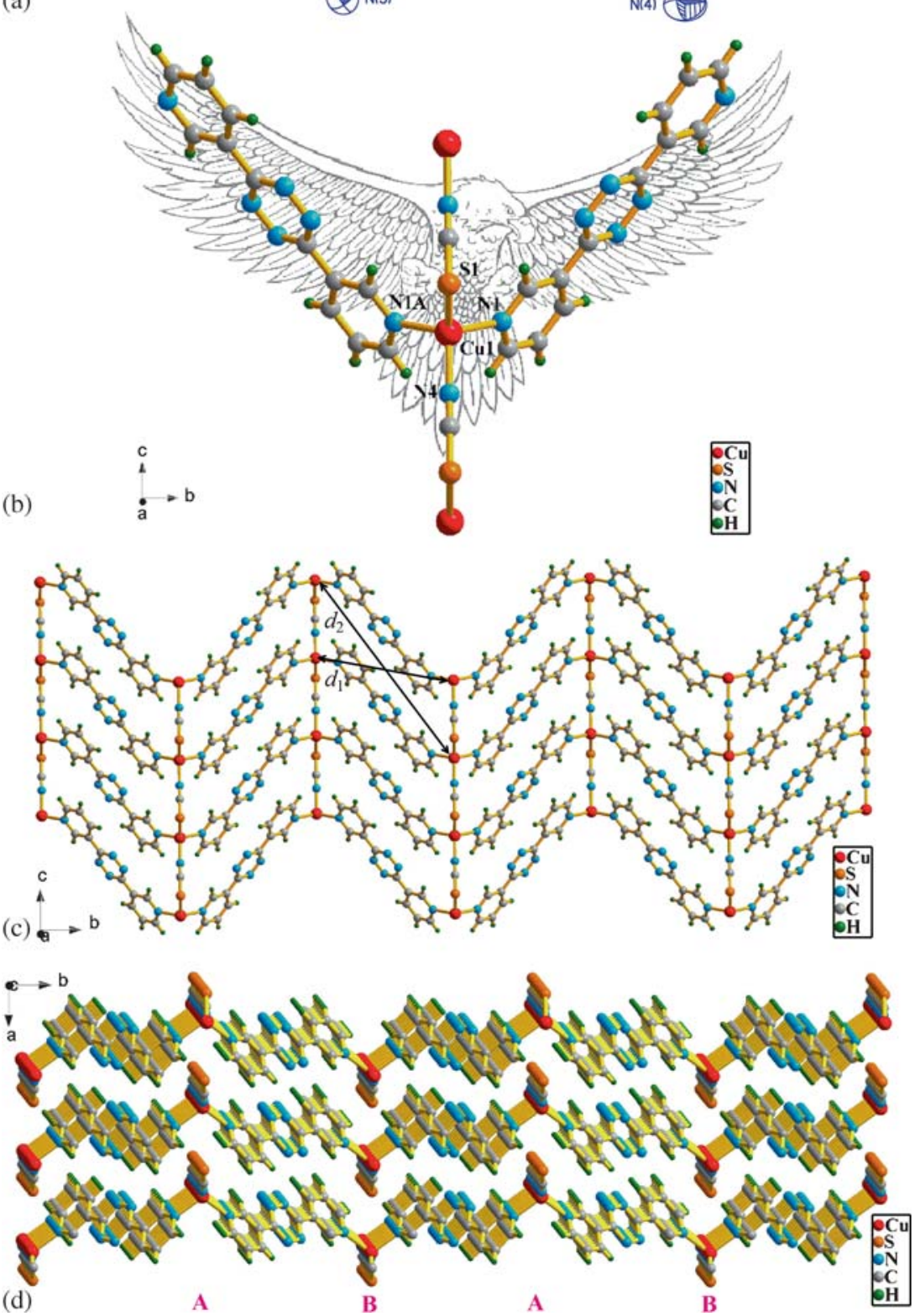

Figure 2. (a) The asymmetric unit of $\mathbf{2}$ (30\% probability ellipsoids). (b) A local view, superimposed with the image of spread eagle, showing the coordination geometry of $\mathrm{Cu}(\mathrm{I})$. Symmetry code: $a: \mathrm{x},-\mathrm{y}+1 / 2$, z. (c) The 2D planelike $(4,4)$ layers of 2 along approximately $a$-axis, the diagonal distances 2D grid the $\mathrm{Cu}$ atoms are $d_{1}=11.042(19) \AA$ and $d_{2}=17.361(28) \AA$. (d) Packing diagram of $\mathbf{2}$ viewed down the $c$-axis. All $\mathrm{H}$ atoms are omitted for clarity. 
(a)

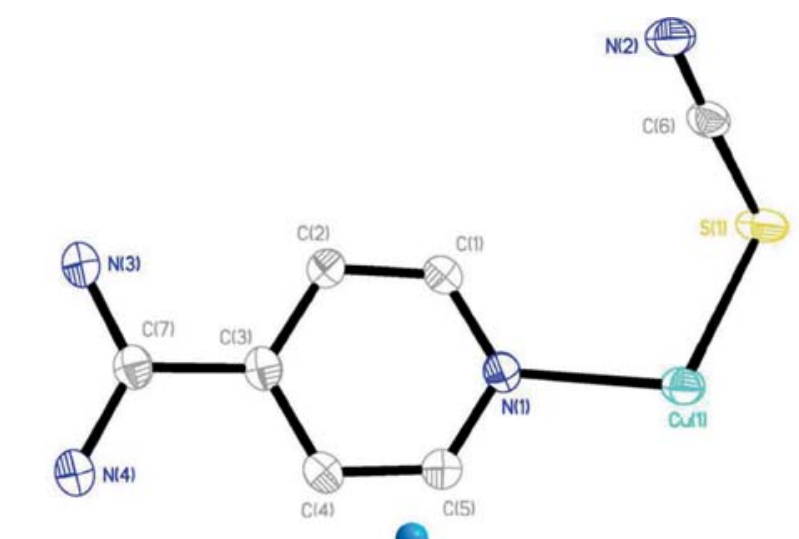

(b)
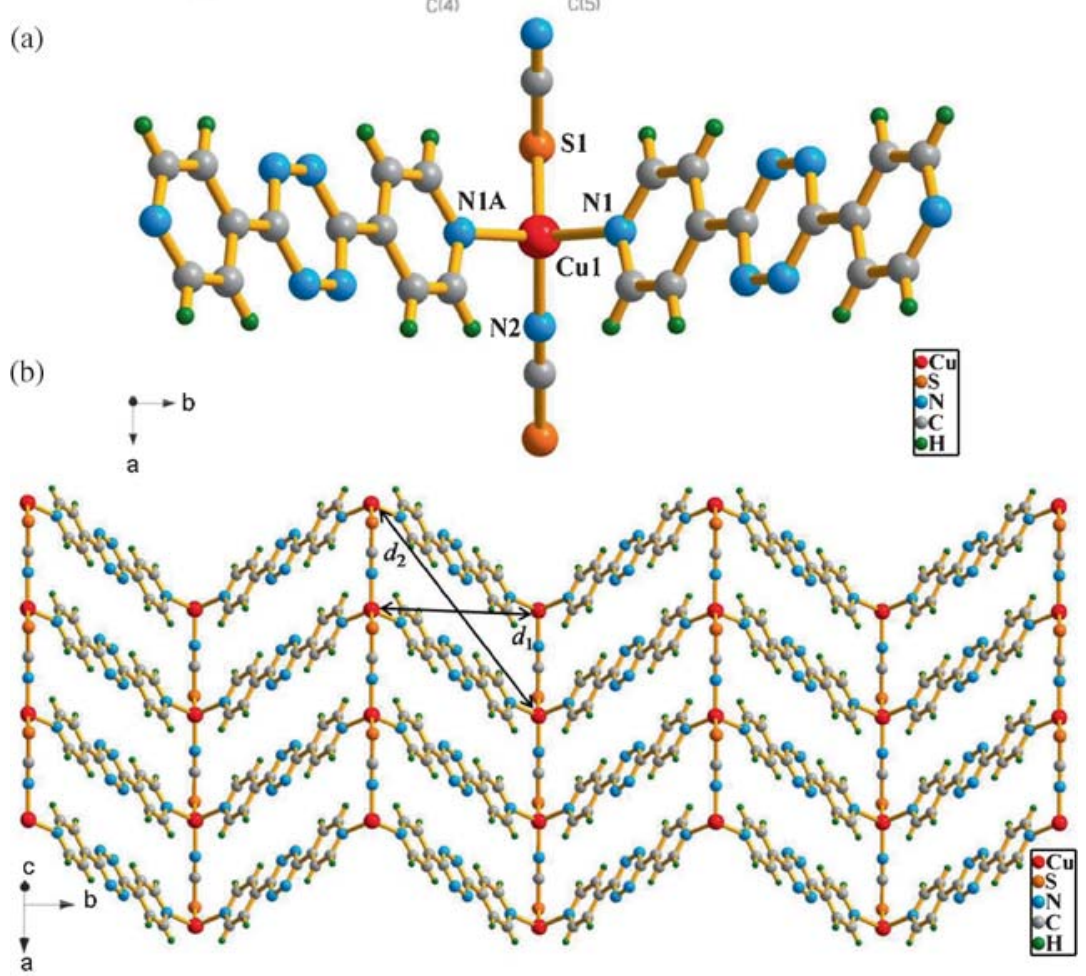

(c)

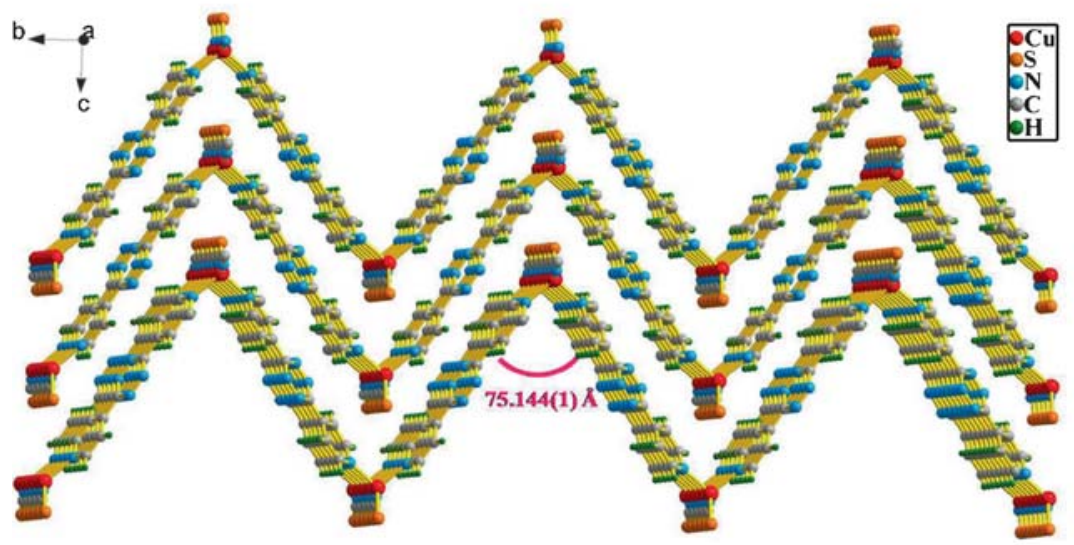

(d)

Figure 3. (a) The asymmetric unit of 3 (30\% probability ellipsoids). (b) Coordination environment of $\mathrm{Cu}(\mathrm{I})$. Symmetry code: $a$ : $\mathrm{x},-\mathrm{y}+1 / 2$, z. (c) The 2D saw-tooth wavy $(4,4)$ networks of $\mathbf{3}$ along approximately $c$-axis, the diagonal distances $2 \mathrm{D}$ grid the $\mathrm{Cu}$ atoms are $d_{1}=15.191(32) \AA$ and $d_{2}=17.284(31) \AA$. (d) Packing diagram of $\mathbf{3}$ viewed down the $a$-axis. All $\mathrm{H}$ atoms are omitted for clarity. 


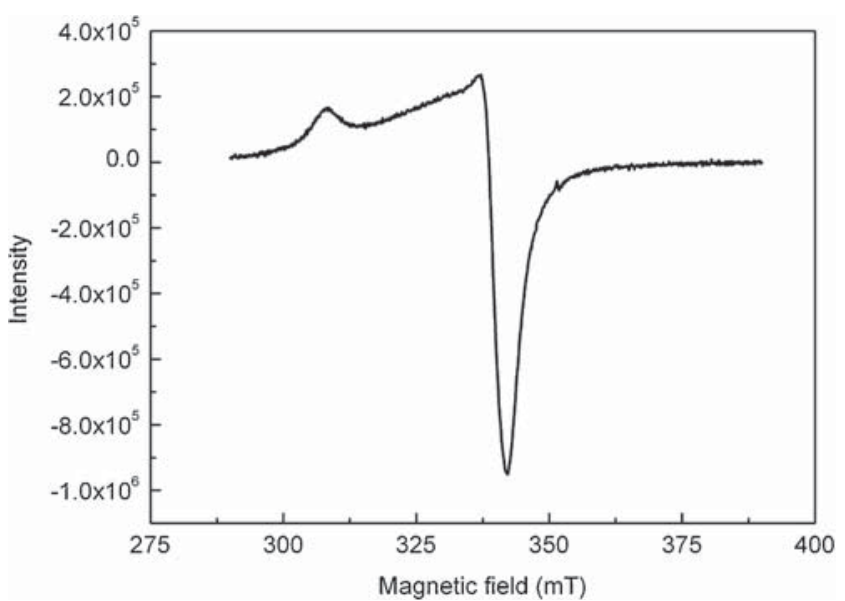

Figure 4. EPR spectrum of $\mathbf{1}$ in powder crystals.

phase purity of the synthesized samples, the powder Xray diffraction (PXRD) patterns of $\mathbf{1 - 3}$ were measured at $298 \mathrm{~K}$. By comparison, they are in good agreement with their corresponding simulated patterns, confirming phase purities of these samples (figure 5).

In order to characterize the thermal stability of $\mathbf{1 - 3}$, the thermogravimetric analyses (TGA) of polycrystalline samples were carried out at the heating rate $10^{\circ} \mathrm{C} \cdot \mathrm{min}^{-1}$ from $25-700^{\circ} \mathrm{C}$ under air atmosphere. As shown in figure 6 , the red TGA curve shows that as-synthesized 1 releases two coordinated DMF molecule per formula unit (observed $25.75 \%$, calc. $25.99 \%$ ) below $193^{\circ} \mathrm{C}$ and one 3,3'-bptz molecule per formula unit (observed $41.53 \%$, calc. 41.98\%) below $439^{\circ} \mathrm{C}$. Such thermal stability is also similar to that reported $\mathrm{Cu}(\mathrm{II})-\mathrm{CPs}$ based on solvent and $\mathrm{N}$ containing ligands. ${ }^{28}$ The orange TGA curve shows that as-synthesized 2 releases one 3,3'-bptz molecule per formula unit (observed $36.05 \%$, calc. 34.06\%) below $454^{\circ} \mathrm{C}$. The blue TGA curve shows that assynthesized 3 releases one 4,4'-bptz ligand per formula unit (observed $37.30 \%$, calc. $34.06 \%$ ) below $465^{\circ} \mathrm{C}$. The thermal behavior of $\mathbf{2}$ and $\mathbf{3}$ are consistent with the result of $\left[(\mathrm{CuSCN})_{3}(\mathrm{Hbppz})\right]_{\mathrm{n}}(\mathrm{Hbppz}=3,5-$ bis(3-pyridyl)-1 $H$-pyrazole) reported by Li et al., even though some differences are present in these CPs. ${ }^{29}$

\subsection{Photoluminescent properties}

Taking into account the excellent photoluminescent properties of CPs with transition metal centers and organic conjugated ligands, ${ }^{30,31}$ and the photoluminescence of 3,3'-bptz, 4,4'-bptz ligands, CPs 1-3 have been investigated in the solid state at room temperature (figures 7-9). As shown in figure 7, it can be seen that upon excitation at $458 \mathrm{~nm}, \mathrm{CP} \mathbf{1}$ exhibited
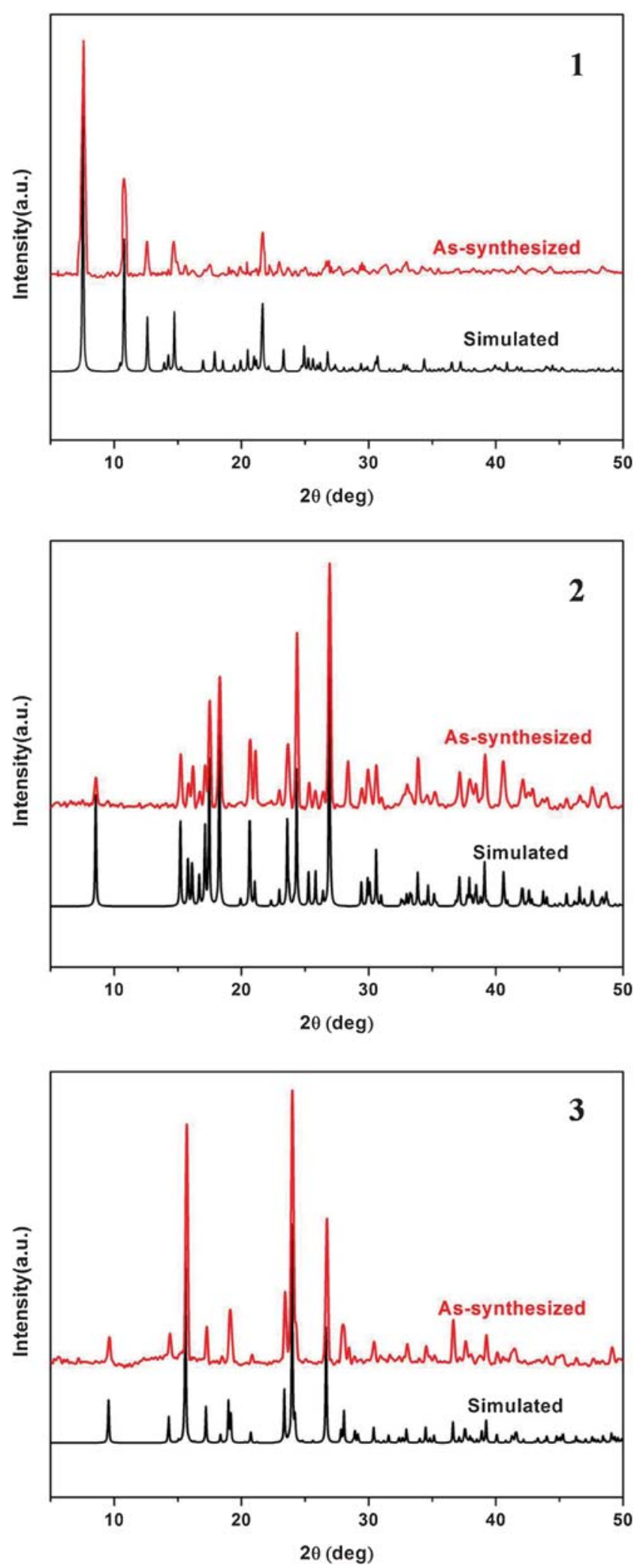

Figure 5. Experimental and simulated X-ray diffractograms of 1-3 as powder.

emission peak at $589 \mathrm{~nm}$. Emission peak at $735 \mathrm{~nm}$ $\left(\lambda_{\mathrm{ex}}=549 \mathrm{~nm}\right)$ for 3,3'-bptz ligand was monitored. The emission peak of $\mathbf{1}$ is blue-shifted by about $146 \mathrm{~nm}$ 


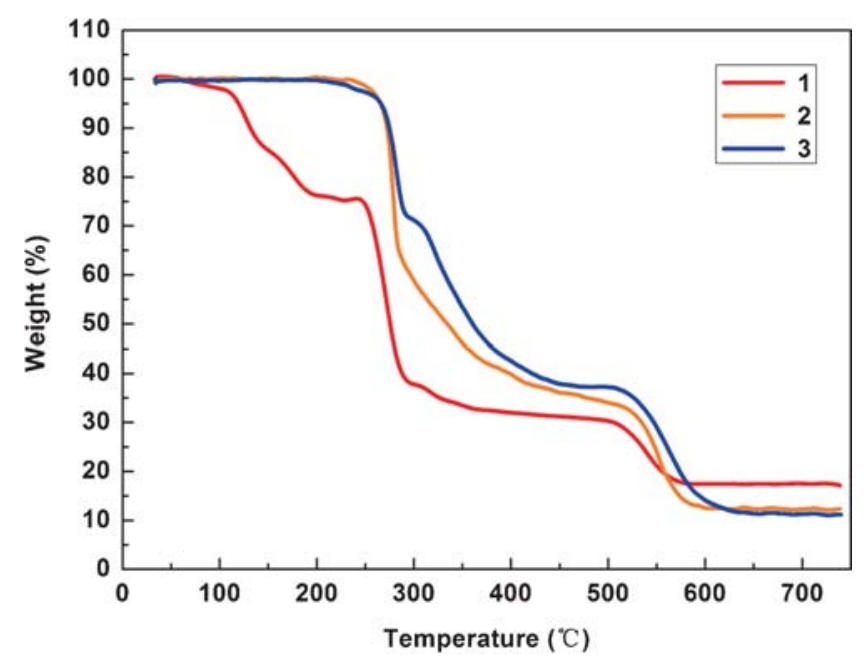

Figure 6. Thermogravimetric curves of 1-3.

compared to pure $3,3^{\prime}$-bptz ligand. It is clear that the coordination bonds significantly improve the luminescence intensity of 3,3'-bptz ligand by enhancing the structural rigidity and reducing the fluorescence quenching effect. ${ }^{32,33}$ As displayed in figure 8, CP 2 displayed intense fluorescent emission at $591 \mathrm{~nm}$ with excitation at $471 \mathrm{~nm}$. It is noted that the emission of 2 show a blue shifted peak by about $144 \mathrm{~nm}$ compared with 3,3'-bptz ligand. Such photoluminescence behavior suggest that the emission band of $\mathbf{2}$ is mainly due to pseudohalide-to-ligand charge-transfer (XLCT) as reported for $\mathrm{Cu}$ metal complexes with $\mathrm{N}$-donor ligands. ${ }^{34,35}$ As illustrated in figure 9, upon excitation at $407 \mathrm{~nm}$, CP 3 revealed a strong emission peak at $526 \mathrm{~nm}$. For the $484 \mathrm{~nm}$ excitation, the emission maximum of the 4,4'-bptz ligand can be observed at $625 \mathrm{~nm}$. The emission peak of $\mathbf{3}$ is significantly blue-shifted by about $99 \mathrm{~nm}$. This may be ascribed to the coordination effects of the 4,4'-bptz ligands to the metal ions, which reduce the nonradiative decay of the intraligand and increase the conformational rigidity of the ligands. ${ }^{36,37}$ This observation indicates that the CPs may be good candidates as photoluminescent materials.

\section{Conclusion}

In summary, we have synthesized and characterized three $\mathrm{Cu}$-based coordination polymers, CPs $\mathbf{1 - 3}$ which feature interesting 1D chain, 2D plane, and 2D sawtooth networks. Thiocyanates behave as terminal ligands in CP 1, while they become bridged ligands to coordinate with two metal centers in CPs $\mathbf{2}$ and $\mathbf{3}$. CPs 2 and $\mathbf{3}$ are structural isomers, which have different 2D $(4,4)$ networks because of the ligands' position isomerism. These structural analyses reveal that the valence state of metal ions and positional isomeric effect of ligands have important influences on the final

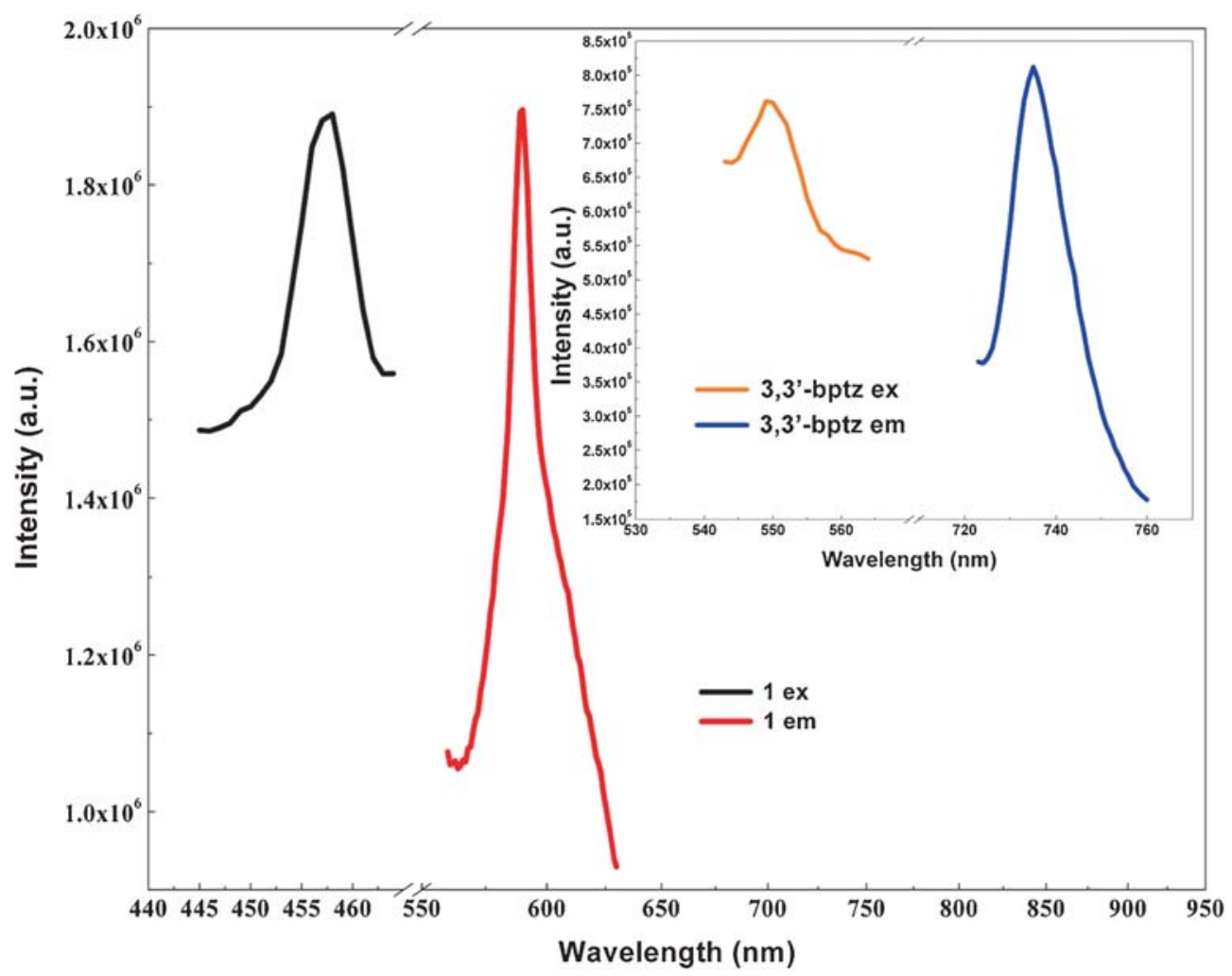

Figure 7. Solid state excitation and emission spectra of $\mathbf{1}$ and 3,3'-bptz (inset) at room temperature. 


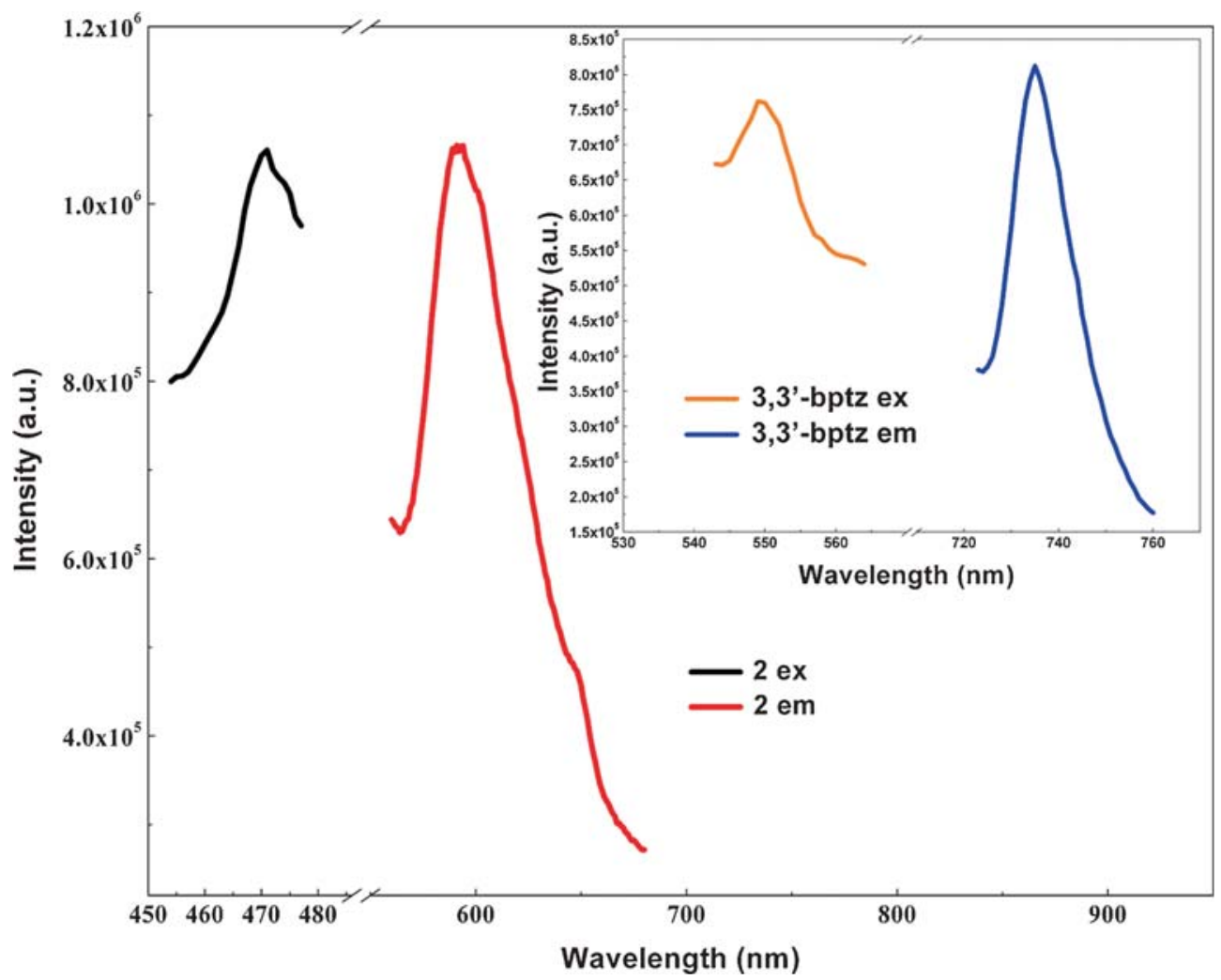

Figure 8. Solid state excitation and emission spectra of $\mathbf{2}$ and 3,3'-bptz (inset) at room temperature.

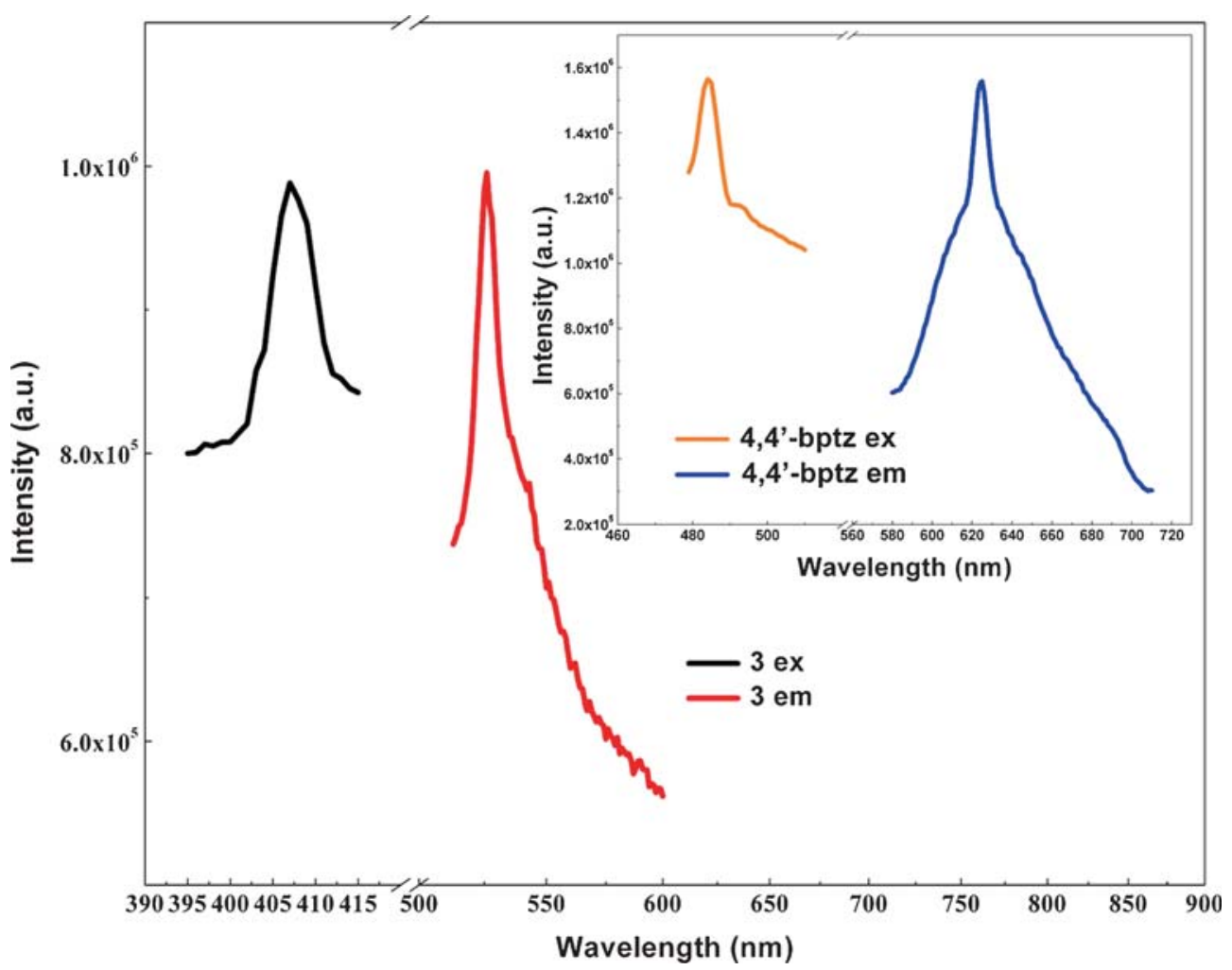

Figure 9. Solid state excitation and emission spectra of $\mathbf{3}$ and 4,4'-bptz (inset) at room temperature. 
structures. TG and PXRD were performed, which confirmed the consistent composition with the single crystal X-ray data. In addition, the photoluminescence studies of CPs 1-3 exhibit blue-shifted emissions, compared to 3,3'-bptz / 4,4'-bptz ligands. To explore the construction of novel CPs with interesting properties incorporating pseudohalogen and pyridyl derivative ligands is underway.

\section{Supplementary Information}

CCDC 972993, 972961 and 972962 contain the supplementary crystallographic data for 1-3. The data can be obtained free of charge via $<$ http://www.ccdc.cam. ac.uk/conts/retrieving.html>, or from the Cambridge Crystallographic Data Centre, 12 Union Road, Cambridge CB2 1EZ, UK; fax: (+44) 1223-336-033; or e-mail: deposit@ccdc.cam.ac.uk. The FT-IR spectra (figure S1) of CPs 1-3 are reported in Supplementary Information which is available at www.ias.ac.in/ chemsci.

\section{Acknowledgements}

Financial support from the National Natural Science Foundation of China (51432006, 50925207, 51172100), the Ministry of Science and Technology of China for the International Science Linkages Program (2009DFA50620, 2011DFG52970), the Ministry of Education of China for the Changjiang Innovation Research Team (IRT14R23), the Ministry of Education, the State Administration of Foreign Experts Affairs for the 111 Project (B13025), Jiangsu Innovation Research Team and the Research Foundation of Jiangsu University (13JDG042) are gratefully acknowledged.

\section{References}

1. Zheng Y-Z, Zheng Z and Chen X-M 2014 Coord. Chem. Rev. 1258

2. Du M, Li C-P, Liu C-S and Fang S-M 2013 Coord. Chem. Rev. 2571282

3. Masoomi M Y and Morsali A 2012 Coord. Chem. Rev. 2562921

4. Heine J and Müller-Buschbaum K 2013 Chem. Soc. Rev. 429232

5. Kole G K and Vittal J J 2013 Chem. Soc. Rev. 421755

6. Luo Y-H, Gu L-L, Yu X-Y, Yue F-X, Chen X and Zhang H 2014 Inorg. Chem. Comm. 40176

7. Yang P, Wu J-J, Zhou H-Y and Ye B-H 2011 Cryst. Growth Des. 1299

8. Xing F, Bai Y, He X, Jia J, Zhou D, Shao M and Zhu S 2012 Cryst. Eng. Comm. 144312

9. Bohnsack A M, Ibarra I A, Bakhmutov V I, Lynch V M and Humphrey S M 2013 J. Am. Chem. Soc. 13516038
10. Seth P, Bauzá A, Frontera A, Massera C, Gamez P and Ghosh A 2013 Cryst. Eng. Comm. 153031

11. Aragoni M, Arca M, De Pasquale M, Devillanova F, Isaia F, Lippolis V, Champness N, Oxtoby N and Wilson C 2005 Cryst. Eng. Comm. 7363

12. Lu Z Z, Zhang R, Pan Z R, Li Y Z, Guo Z J and Zheng H G 2012 Chem. Eur. J. 182812

13. Li D, Wu T, Zhou X P, Zhou R and Huang X C 2005 Angew. Chem. Int. Ed. 444175

14. Barnett S A, Blake A J, Champness N R and Wilson C 2002 Chem. Commun. 1640

15. Mukherjee G and Biradha K 2012 Chem. Commun. 48 4293

16. Hijikata $\mathrm{Y}$, Horike $\mathrm{S}$, Sugimoto $\mathrm{M}$, Inukai $\mathrm{M}$, Fukushima T and Kitagawa S 2013 Inorg. Chem. 52 3634

17. Li J, Peng Y, Liang H, Yu Y, Xin B, Li G, Shi Z and Feng S 2011 Eur. J. Inorg. Chem. 172712

18. Oxtoby N S, Blake A J, Champness N R and Wilson C 2003 Cryst. Eng. Comm. 582

19. CrystalClear 2002 (Version 1.3.5) (Tokyo: Rigaku Corporation)

20. Sheldrick G M 1997 SHELXS 97 and SHELXL 97, Programs for Crystal Structure Refinement (Göttingen: University of Göttingen)

21. Luo G-G, Xiong H-B and Dai J-C 2011 Cryst. Growth Des. 11507

22. Hou L, Li D, Shi W-J, Yin Y-G and Ng S W 2005 Inorg. Chem. $\mathbf{4 4} 7825$

23. Wu Y, Meng Q and Zhang C 2010 Acta Crystallogr. E $66 \mathrm{~m} 217$

24. Kamalaker V, Upender G, Prasad M and Chandra M V 2010 Indian J. Pure Ap. Phy. 48709

25. Biyik R, Tapramaz R and Yeşilel O Z 2007 Spectrochim. Acta A 68394

26. Miller K M, McCullough S M, Lepekhina E A, Thibau I J, Pike R D, Li X, Killarney J P and Patterson H H 2011 Inorg. Chem. $\mathbf{5 0} 7239$

27. Bellamy L J 1975 In The Infra-red Spectra of Complex Molecules (London: Chapman and Hall)

28. Yang W-T, Yi F-Y, Li X-D, Wang L, Dang S and Sun Z-M 2013 RSC Adv. 325065

29. Zhan S-Z, Peng R, Lin S-H, Ng S-W and Li D 2010 Cryst. Eng. Comm. 121385

30. Vitale M and Ford P C 2001 Coord. Chem. Rev. 219 3

31. Yam V W-W and Lo K K-W 1999 Chem. Soc. Rev. 28 323

32. Gong Y, Liu J-Z, Hu C-W and Gao W-L 2007 Inorg. Chem. Commun. 10575

33. Cheng Y-F, Lu X-M and Wang G 2014 Dalton Trans. 43 5357

34. Yang J-H, Wu X-Y, He R-T, Ren Z-G, Li H-X, Wang H-F and Lang J-P 2013 Crystal. Growth Des. 13 2124

35. Zhang L, Ren Z-G, Li H-X and Lang J-P 2011 Cryst. Eng. Comm. 131400

36. Kan W-Q, Yang J, Liu Y-Y and Ma J-F 2012 Inorg. Chem. 5111266

37. Dai F-N, He H-Y, Gao D-L, Ye F, Sun D-F, Pang Z-J, Zhang L, Dong G-L and Zhang C-Q 2009 Inorg. Chim. Acta 3623987 